\title{
The development of shale micro nano-scale fractures and the relationship between its influencing factors and the micro-fracture space
}

\author{
Yang Chunmei ${ }^{1, a}$, Bai Yongqiang ${ }^{1,2, b}$, Zhu Lunwei ${ }^{3, c}$ and Liu Mei ${ }^{1, d}$ \\ ${ }^{1}$ Electronic Science College, Northeast Petroleum University, the University-enterprise R \& D \\ Center of Measuring and Testing Technology \& Instrument and Meter Engineering in Heilongjiang \\ Province, Daqing, 163318, China \\ ${ }^{2}$ Unconventional Gas Research Institute, China University of Petroleum, Beijing, 102249, China \\ ${ }^{3}$ Geoscience College, Northeast Petroleum University, Daqing, Heilongjiang

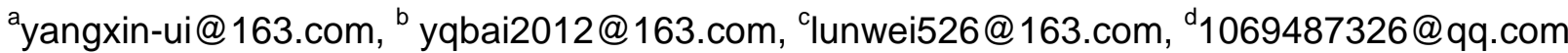

\begin{abstract}
Keywords: micro-fractures; Longmaxi Formation; shale gas; brittle mineral; JY1 well
Abstract. To explore the development and influence factors of shale micro-fractures, we used SEM and AFM to observe the shale samples of JY1 well. There are some factors from these pictures: the surfaces of JY1 well are ups and downs; the difference is up to micron level; the micro-fractures connected widely. These expand the reservoir space and storage shale gas. X-ray measured and analyzed mineral composition content of JY1 well, and its brittle mineral content is more than 70\%, which it makes the development of micro-fractures good. Many AFM images were processed by the MATLAB software with the integral method. The ratio was calculated of effective volume of micro-fractures to actual shale volume (Percentage of micro-fractures for short). There is a good positive correlations relationship between BET, TOC, desorbed gas and organic pore with percentage of micro-fractures.
\end{abstract}

\section{Introduction}

After years of exploration and research, the shale is an important place to reservoir shale gas source, which located in Longmaxi formation of southern Sichuan ${ }^{[1]}$. Domestic and international understanding of the exploration and development of organic shale show that artificial fracturing of shale can form a network fracture system. It improves the effective reservoir of shale gas. So the development level of the fracture determines the efficiency of the shale gas production and the quality and quantity of the shale gas $^{[2]}$. The development degree of the fractures in shale is directly related to the brittle mineral, and related to BET, TOC and organic pore. There are total 6 samples, which were taken from $2353 \mathrm{~m}-2451 \mathrm{~m}$ deep well section as acquisition research area of JY1 well in Fuling Chongqing. The development of fractures was analyzed by X-ray diffraction, scanning electron microscopy and atomic force microscopy. Then the radio was calculated of effective volume of micro-fractures to actual shale volume (Percentage of micro-fractures for short). Finally percentage of micro-fractures relationship with BET, TOC, desorbed gas and organic pore were established.

\section{The Characteristics of Shale Fractures in Longmaxi Formation}

The shale gas reservoir layer is black, rich organic carbon, large thickness, and mainly concentrated in the lower-Longmaxi formation in Silurian. The developed fracture system in the shale reservoir is not only beneficial to the enrichment of free gas, but it is the main channel of shale gas flow, which plays a key role in the development of shale gas ${ }^{[3]}$.

Fractures Characteristics. The development of fractures in shale is favorable for gas enrichment and analysis. According to the width of the fractures were divided into five levels, namely micro-fractures (Width is less than $0.1 \mathrm{~mm}$ ), small fractures (Width is between $0.1-1 \mathrm{~mm}$ ), middle fractures (Width is between 1-10mm), big fractures (Width is between 10-100mm), and huge fractures (Width is bigger $100 \mathrm{~mm})^{[4]}$. At the macro level, shale can observe fractures along the direction of foliation (Fig. 1A). The fracture surface is usually straight and smooth, there also with micro scratches 
or dislocation phenomenon on the fracture surface (Fig. 1B). The length of micro-fractures is up to $90 \mu \mathrm{m}$, when it is observed under the scanning electron microscope, and the fractures are filling with framboidal pyrite, calcite and organic matter and so on. Mineral grains are sparse relatively, so shale of JY1 well has a large amount of hydrocarbon generation, large gas storage space, and a strong permeability (Fig. 1C and Fig. 1D). After the atomic force microscope, the surface of the undulating shale was obviously observed. Microscopic fluctuation difference may reach $30 \mu \mathrm{m}$ (Fig. 1E), there also exits difference in $800 \mathrm{~nm}$ (Fig. 1F). We can get the relationship between the space location and the quality of connecting micro-fractures in three-dimensional pictures, which was transformed by AFM images (Fig. $1 \mathrm{G}$ and Fig. 1H).
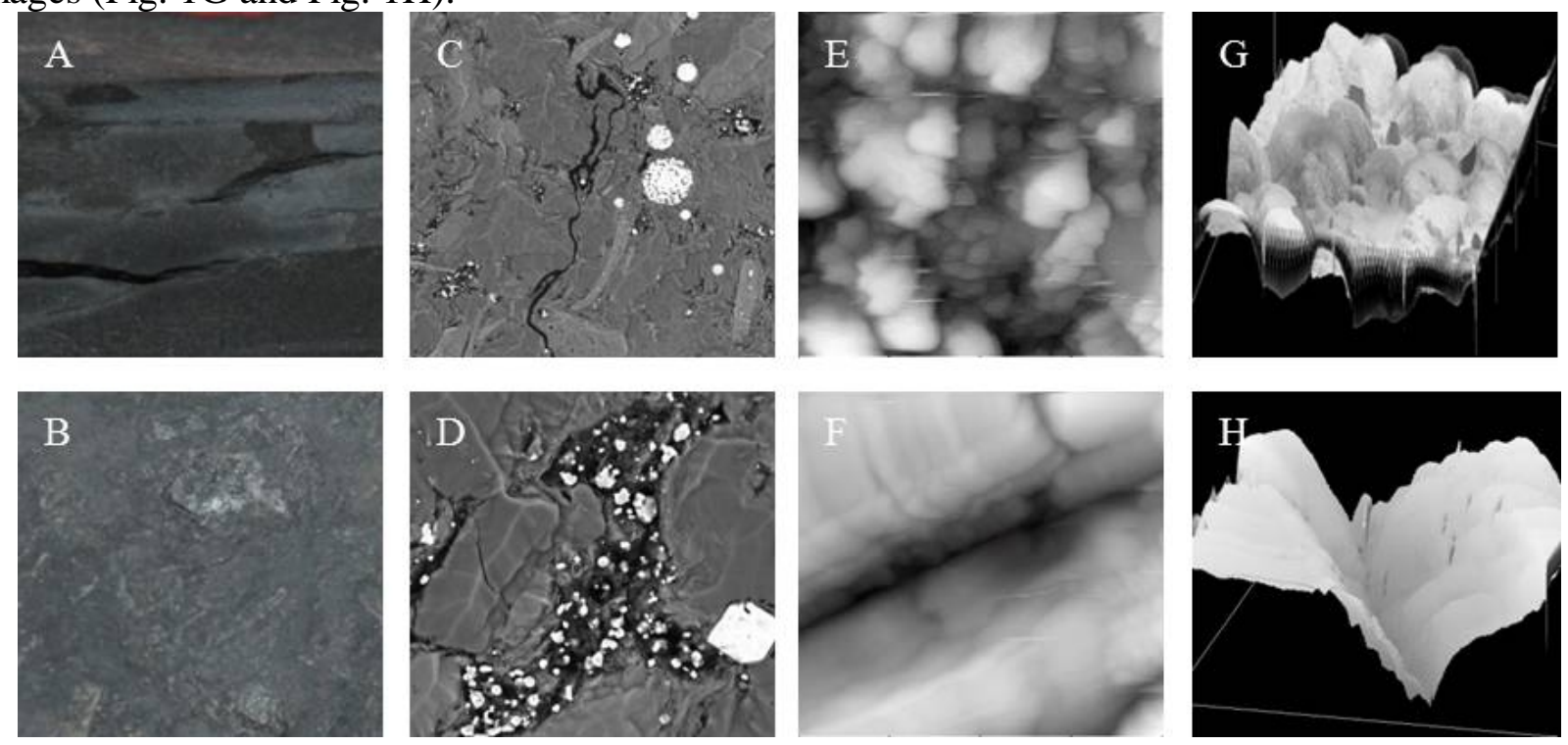

Figure 1 Characteristics of fractures in shale of JY1 well in Longmaxi formation

Shale Mineral Composition. The mineral composition of shale and its content have an important influence on the development of fractures and gas storage ${ }^{[5]}$. Through the analysis of the brittle mineral content of JY1 well samples, found that the main components are quartz, dolomite, plagioclase, and calcite, with a small certain amount of potash feldspar and pyrite, a small amount of barite, gypsum, etc. The relative content of clay minerals found mainly illite and chlorite.

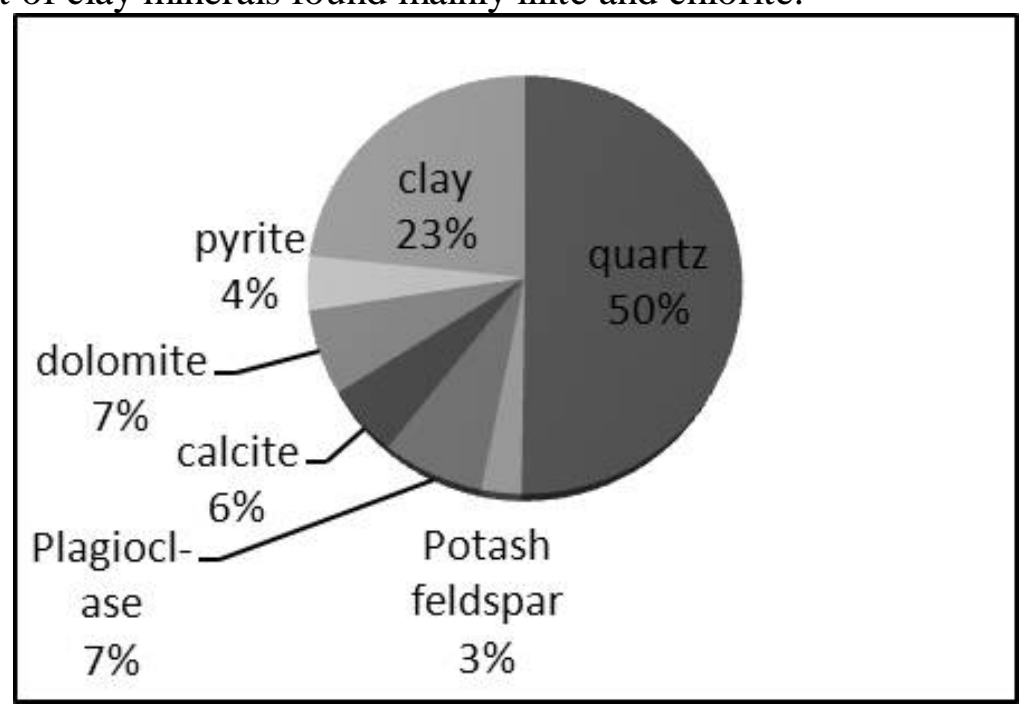

Figure 2 Average percentage content of minerals

The content of quartz is up to half and brittle mineral content is more than $70 \%$, so it makes the development of micro-fractures good. It improves the amount of gas reservoir space and gas storage (Fig. 2). 


\section{Microscopic Control Factors of Shale Reservoir}

The Actual Micro-fractures Statistical Method. The shale samples were polished and then scanned under AFM microscope. The AMF images reflect the structure of micro-fractures: minerals are fine in size; surrounding pores are more intensive; the difference of ups and downs is big; micro-fractures can meet each other; micro-fractures are diverge widely and with a wide range of connectivity. Many AFM images were processed by the MATLAB software with the integral method. The method of treatment shows as formula 1.

$$
\mathrm{P}=\frac{l w h-\frac{l}{n-1} \cdot \frac{w}{m-1} \cdot \sum_{i=1}^{m} \sum_{j=1}^{n} X(i, j) \cdot \frac{l}{255}}{l w h}
$$

$\mathrm{P}$ is the ratio which was calculated of effective volume of micro-fractures to actual shale volume (Percentage of micro-fractures for short); 1 is the effective length of AFM images; $w$ the effective width of AFM images; $h$ is the highest peaks; $n$ is the number of pixels in length of AFM images which is converted to gray scale $8 ; \mathrm{m}$ is the number of pixels in width of AFM images which is converted to gray scale $8 ; \mathrm{X}(\mathrm{i}, \mathrm{j})$ is the gray value of pixels in the matrix of image data generation There are some characteristic parameters of different segment of JY1 well (Table 1).

Table 1 Characteristic parameters of different segment of JY1 well

\begin{tabular}{c|c|c|c|c|c}
\hline Deep & $\mathrm{P}(\%)$ & $\mathrm{BET}\left(\mathrm{m}^{2} / \mathrm{g}\right)$ & $\mathrm{TOC}(\%)$ & Desorbed gas $\left(\mathrm{m}^{3} / \mathrm{t}\right)$ & Organic pore \\
\hline 2353.00 & 0.41 & 15.70 & 2.618 & 0.95 & 0.012 \\
\hline 2357.00 & 0.39 & 8.79 & 1.051 & 0.80 & 0.002 \\
\hline 2386.00 & 0.45 & 11.94 & 1.903 & 4.05 & 0.021 \\
\hline 2391.00 & 0.46 & 15.65 & 2.704 & 2.55 & 0.026 \\
\hline 2410.50 & 0.46 & 18.00 & 2.069 & 4.20 & 0.022 \\
\hline 2415.00 & 0.45 & 18.99 & 3.764 & 3.60 & 0.018 \\
\hline
\end{tabular}

Relationship between Fractures Influence Factors and Percentage of Micro-fractures. The amount of shale gas in shale reservoir depends on BET specific surface area of the matrix pores. Test results show that the BET specific surface area of shale reservoir in the study area is among $8.79 \mathrm{~m}^{2} / \mathrm{g}-18.99 \mathrm{~m}^{2} / \mathrm{g}$, and average is $14.85 \mathrm{~m}^{2} / \mathrm{g}$. The BET specific surface area of shale in the study area is large, which is beneficial to the adsorption of shale gas. Build relationship between BET and percentage of micro-fractures (Fig. 3A).
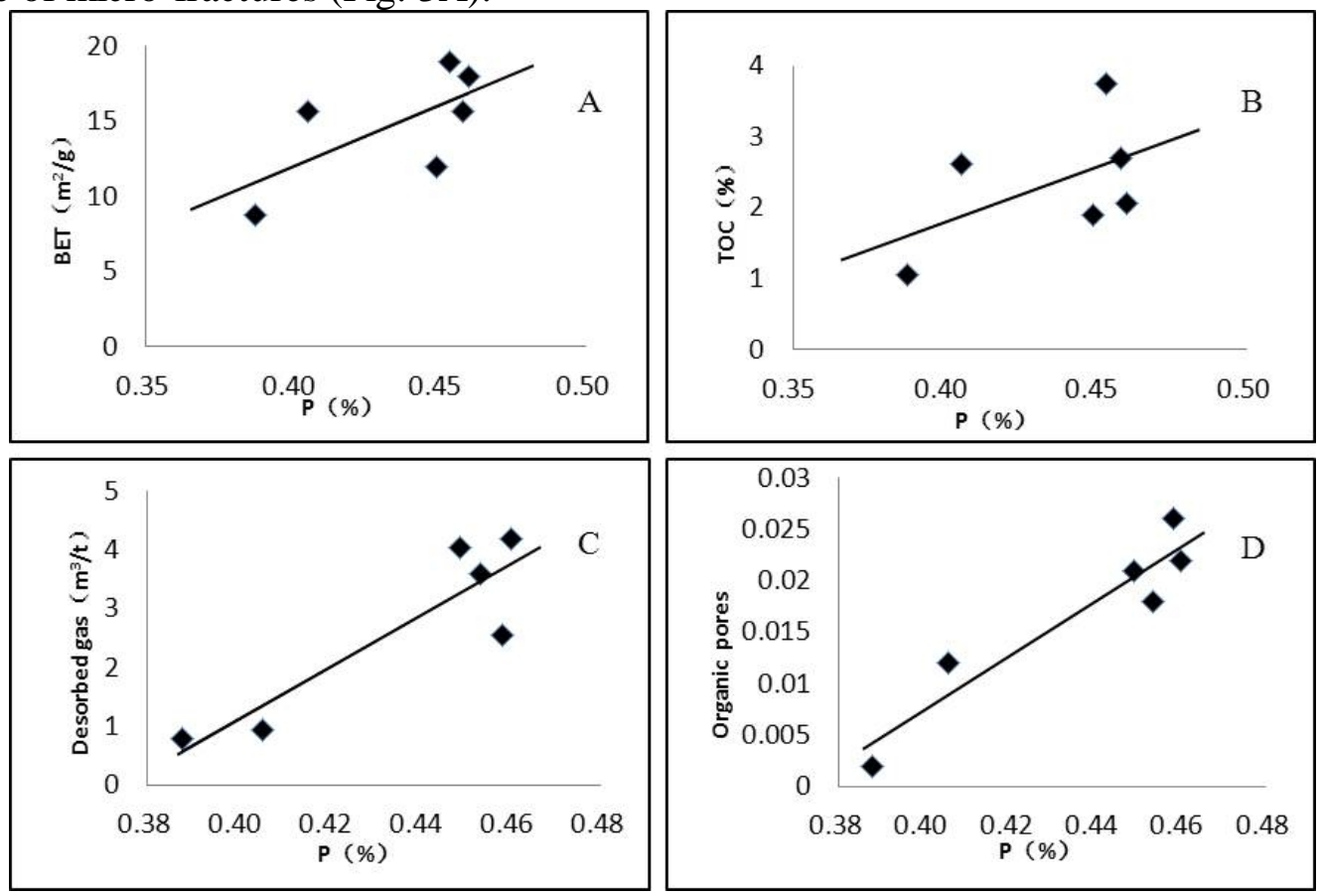

Figure 3 Relationship between fractures influence factors and percentage of micro-fractures 
TOC (Total organic carbon) content not only controls the content of shale gas, but also controls the degree of development of shale fractures. TOC content is $1.051 \%-3.764 \%$, and the average value is $2.35 \%$ of JY1 well. Build relationship between TOC and percentage of micro-fractures (Fig. 3B).

We get the amount of desorbed gas of field measurement. Build the relationship between desorbed gas and percentage of micro-fractures (Fig. 3C). According to the statistical data, eventually found that the percentage of micro-fractures has a good positive correlation with desorbed gas.

The size of organic matter is determined to the capacity of shale gas storage capacity. Therefore establish the relationship between the organic matter and the percentage of micro-fractures. There is a good positive correlation in them (Fig. 3D).

\section{Conclusions}

1. The fractures of JY1 well connect widely in Longmaxi formation, and its brittle mineral content is more than $70 \%$. So the micro-fractures development is good.

2. There is good positive relationship between BET, TOC, desorbed gas and organic pore and percentage of micro-fractures in Longmaxi formation.

\section{Acknowledgements}

This work was financially supported by the Natural Science Foundation of China (No. 51274068, No. 41474112), the China Postdoctoral Science Foundation (No. 2014M560163) and the Ministry of Education Key Laboratory of Foundation (Enhanced Oil Recovery).

\section{References}

[1] Zou C N, Dong D Z, Wang S J, et al. Geological Characteristics, formation Mechanism and Resource Potential of Shale Gas in China[J]. Petroleum Exploration and Development. Vol. 37 (2010), p. 641-653.

[2] Chen S B, Zhu Y M, Wang H Y, et al. Characteristics and Significance of Mineral Compositions of Lower Silurian Longmaxi Formation Shale Gas Reservoir in the Southern Margin of Sichuan Basin[J]. ACTA Petrolei Sinica. Vol. 32 (2011), p. 775-782.

[3] M. Rahmanian, N. Solano and R. Aguilera. Storage and output ow from shale and tight gas reservoirs. In: Proceeding of SPE Western Regional Meeting, Anaheim, California. Vol. 5 (2010). p. 27-29.

[4] Wang Y M, Dong D Z, Yang H, et al. Quantitative characterization of reservoir space in the Lower Silurian Longmaxi Shale, southern Sichuan, China[J]. Science China: Earth Sciences. Vol. 44 (2014), p. 1348-1356.

[5] Ding W L, Li C, Li C Y, et al. Fractured Development in Shale and Its Relationship to Gas[J]. Geoscience Frontiers. Vol. 3 (2012), p. 97-105. 